\title{
Spatial Operation of a Regional Food Supply System Based on Adapted Development of Competitive Agroclusters
}

\author{
Elena Dorzhieva \\ Production Economics, Organization and Administration \\ Department \\ East Siberia State University of Technology and \\ Management \\ Ulan-Ude, Russia \\ elendorg@mail.ru
}

\author{
Evdokia Dugina \\ Production Economics, Organization and Administration \\ Department \\ East Siberia State University of Technology and \\ Management \\ Ulan-Ude, Russia \\ Dugina2003@mail.ru
}

\begin{abstract}
The article examines some aspects of the functioning of a regional food supply system, identifies the level of self-sufficiency of subjects of the Russian Federation located in the Baikal region, the main foodstuffs, and the need for the development of interregional food ties. We have made an analysis of tendencies of development of regional agro-industrial complex and substantiated expediency of an inter-regional agro-ecological cluster in the Baikal region, specializing in organic livestock, capable of functioning effectively in the face of environmental constraints imposed in connection with the need to protect Lake Baikal. Baikal region is studied as a unified socio-ecological system in need of strengthening and deepening of interregional connections, one of promising areas of development of which is the agricultural sector, which brings synergistic socio-ecological and economic effect in the formation of agricultural clusters.
\end{abstract}

Keywords: agro-industrial complex, clusters, agro-ecological cluster, sustainable development of the Baikal region, synergistic socio-ecological and economic effect, organic livestock, food supply, self-sufficiency level, interregional communications

\section{INTRODUCTION}

One of the megatrends of the 21 st century is the increase in food prices due to population growth (by 2030 it will reach 8.3 billion people) and limited resources (the demand for food, water and energy is projected to increase by 35,40 and $50 \%$ respectively, while increasing environmental risks and threats related to human destructive activities and human overconsumption, the rate of which exceeds the capacity to restore the environment) [1]. The problems of food supply and food security, with the introduction of economic sanctions and counter-sanctions, have only worsened, and they need to be addressed not only at macro but also at the meso levels. The economic crisis has worsened an already significant interregional differentiation, because of which socioeconomic and agricultural production potentials have concentrated in the central regions of the country that are characterized by favorable bioclimatic conditions and closely located markets for food products. Now there is a need to synchronize the spatial organization of agriculture and the socio-economic development of territories through the rational distribution of agricultural production, deepening its specialization, diversifying the rural economy, creating and promoting unique local brands that use the sustainable competitive advantages of the regions in which they emerged [2]. For regions of risky agriculture, the extensive economic development of which is limited by established environmental restrictions (e.g., the Baikal region, whose mission is to preserve the unique ecosystem of Lake Baikal for future generations), organic agricultural production can be a promising direction of development.

The use of new forms of agribusiness organization, such as agricultural clusters, will contribute significantly to improving the self-sufficiency of the regions with basic foodstuffs. Their widespread distribution, alongside with traditional categories of farms, will increase technological diversity and the sustainability of the agricultural economy.

In this article, the authors consider the Baikal region as a spatial unit with a special mission (see above) and its consequent common socio-ecological and economic goals, values, and interests. The development of agroclusters specializing in organic products fits within the framework of this approach and is of interest in terms of the future prospects of greening the regional economy.

\section{LITERATURE REVIEW AND METHODS}

The first studies of the relationship between cluster development and competitiveness appeared in the United 
States and are related to the name of Professor M. Porter [3, 4]. The cluster model of industrial organization in the Siberian Federal District was studied by L.S. Markov and M.A. Yagolnitser, who categorized Siberian regions into three groups from the point of view of clustering prospects: of the three constituent entities of the Russian Federation included in the Baikal region, two - the Republic of Buryatia (RB) and the Trans-Baikal Territory (TB) - are assigned to the third (last) group due to the smaller industry differentiation of successful companies, worse educational level, lower innovative potential and investment attractiveness, and underdeveloped services $[5,6]$. However, we need to note that they were considering the industrial sphere, not the agricultural one.

Currently, there is clearly not enough scientific papers on the problems of cluster development of the AIC: on the scale of the global clustering of the world economy and a huge number of theoretical and practical research on the subject, the "agricultural" direction can be considered to be in its early stages of formation. The most interesting and system-forming works in this area belong to A.S. Khukhrin, A.E. Romanova, V.P. Arashukov, A.S. Boytsov, and A.I. Kostyaev [7, 8, 9, 10]. To summarize their point of view, we can state that in the formation of clusters in the AIC, the social impact on the population of a territory is highly important. Competitive agro-industrial clusters play a serious role not only in the economic development of federal districts, regions, and municipalities, but also in improving food security, ensuring food independence of the country, achieving sustainable rural development, raising the standard of living in rural areas, in short, in matters of social background. The researchers emphasize that the specific principles of clusters that distinguish them from other forms of association are of particular interest. This principle for clusters in the AIC can be synergistic social effect derived from their functioning.

In the context of changes in the technological structure of the AIC, previously attributed to the least innovative and most backward sectors of the economy, it has the opportunity to become the main demonstration platform for the results of the new technological revolution. The role of agricultural clusters in creating the conditions for the transition from the traditional regional economy to the green one and stabilization of the relationship between the technosphere and the biosphere was studied by A.S. Khukhrin, O.I. Bundina, I.Yu. Agnaeva, S.N. Butorin, A.N. Semin, and others [1, 7, 11, 12, 13].

In this study we have used methods of comparison, generalization of the information received, economic and statistical analysis, as well as dialectic method used in the direction of the synergies paradigm.

\section{RESULTS AND DISCUSSION}

A. The specific features of the Baikal region (peripheral location, border, risky farming) determine the need to improve the system of interregional and inter-state food links and increase self-sufficiency in food by taking advantage of unique regional advantages

The achievements of the domestic agricultural sector over the past few years have allowed the state to proclaim it as the driver of Russian economic growth. An important role in this was played by state support for agriculture and the extension of food embargo, which has been in force since 2014. As a result, the Government of the Russian Federation has changed its economic policy priorities: export stimulation now comes to the fore, rather than forced import substitution; the industry has the task of doubling exports by 2024, bringing it to $\$ 45$ billion. The reorientation from import substitution to the active development of exports in 2018 was reflected in the goals and objectives of the national project "Export of agricultural products".

In the same year, the law on organic agriculture was passed; in February 2019, the current state program of agricultural development was extended until 2025, while federal projects "Development of agricultural products export", "Digitalization of agriculture" and "Creating a system for supporting farmers and agricultural cooperation" were included in it [14].

A significant role in the development of the Russian food market was played by the system of mandatory electronic veterinary certification, the introduction of which made it possible to improve the mechanism for ensuring traceability of food products of animal origin and to prevent the entry of lowquality and illicitly manufactured goods into the market (which significantly reduced the risks for consumer health and economic risks for the industry). The work on the large-scale introduction of digital technologies and accelerated modernization, the development of domestic selective breeding and seed production has intensified significantly. However, we should note that the choice of an export-oriented agricultural development strategy can hardly be called the logical result of a successful agricultural policy; rather, it is connected with problems with solvent demand in the domestic market that is decreasing as real incomes drop. The economic recession increased the impact of all negative factors: the low availability of credit resources for producers, underdeveloped infrastructure and logistics, high tax and administrative burden, political uncertainty and instability of the global world order. According to the Deloitte consulting company, only $30 \%$ of Russian agricultural companies rated the prospects for the sector in 2019 as positive (this is the lowest figure during the four years of research); as a result, the "Prospects for the AIC" index dropped from 0.17 to 0.10 [14].

When discussing export opportunities, experts disagreesome believe that the development of export of agricultural raw materials and food can be a catalyst for positive changes in the sector and related industries, while others believe that it is impossible to increase exports to $\$ 45$ billion by 2024 , as Russian agricultural products are not that competitive in foreign markets [15].

The grain group still has the highest growth potential in the existing export strategy: Russia has been the world's leading wheat exporter during the recent years. At the same time, the situation with the production of potatoes, vegetables, fruits and berries remains unsatisfactory; moreover, the 2016 Agricultural Census has revealed huge records that distorted real data. The volume of meat production reached the prereform level of 1989 primarily by increasing the production of 
poultry by 2.5 times. However, the production of cattle meat during the last 30 years has decreased by almost $60 \%$, and milk production has approximately halved. The growth rate of the Russian agricultural economy is uneven and does not meet world standards, as evidenced by the comparative analysis conducted using the corresponding indicators for the U.S. APC [16]. The economic availability of food, the quality and safety of food products sold in Russian consumer market make it impossible to talk about achieving food security for all the basic foodstuffs. The uneven development of agricultural sectors, the imbalance in its organizational structure, depopulation and neglect of rural areas threaten the food selfsufficiency of the country and its regions.

The problems of food supply at the regional level are caused by significant differences between food production and consumption in different parts of the Russian Federation, due to regional geographical, natural and climatic conditions, existing production and economic potential, and social infrastructure. The specificity of food supply of the peripheral regions in the risky agricultural zone lies in the need to develop a rational system of inter-regional food ties and move from regional competition to cooperation and integration.

The Baikal region is one of the regions with poorly developed agriculture, forming food funds mainly through import from other regions and countries. Based on the data of food resource balances, we will analyze the dynamics of selfsufficiency for certain types of agricultural products (Table 1) and the average per capita consumption of basic foodstuffs for 2007-2017 (Table 2) in the Irkutsk region (IR), the Republic of Buryatia (RB) and the Trans-Baikal Territory (TB).

TABLE I. SELF-SUFFICIENCY LEVEL FOR BASIC AGRICULTURAL PRODUCTS, \%

\begin{tabular}{|l|l|l|l|l|l|l|l|l|l|l|l|l|}
\hline Year & $\mathbf{2 0 0 7}$ & $\mathbf{2 0 0 8}$ & $\mathbf{2 0 0 9}$ & $\mathbf{2 0 1 0}$ & $\mathbf{2 0 1 1}$ & $\mathbf{2 0 1 2}$ & $\mathbf{2 0 1 3}$ & $\mathbf{2 0 1 4}$ & $\mathbf{2 0 1 5}$ & $\mathbf{2 0 1 6}$ & $\mathbf{2 0 1 7}$ \\
\hline \multicolumn{10}{|c|}{ Potatoes } \\
\hline IR & 100.0 & 105.3 & 95.1 & 102.2 & 101.1 & 94.9 & 88.8 & 91.3 & 90.3 & 100.3 & 93.0 \\
\hline RB & 100.4 & 110.4 & 109.1 & 101.6 & 101.7 & 98.7 & 89.6 & 82.0 & 75.3 & 95.3 & 76.3 \\
\hline TB & 85.2 & 84.6 & 88.6 & 89.7 & 92.2 & 84.7 & 79.5 & 77.1 & 74.4 & 75.6 & 74.6 \\
\hline \multicolumn{10}{|c|}{ Milk } \\
\hline IR & 94.7 & 93.0 & 89.4 & 86.1 & 83.3 & 81.7 & 84.5 & 86.4 & 86.8 & 86.9 & 87.2 \\
\hline RB & 89.7 & 84.2 & 78.2 & 74.1 & 73.0 & 72.5 & 76.7 & 76.1 & 73.6 & 71.3 & 67.9 \\
\hline TB & 92.2 & 92.9 & 92.8 & 94.0 & 96.3 & 96.0 & 97.6 & 96.6 & 97.0 & 96.7 & 98.8 \\
\hline \multicolumn{10}{|c|}{ Meat } \\
\hline IR & 55.2 & 55.6 & 57.3 & 58.6 & 58.0 & 57.7 & 57.6 & 59.3 & 63.0 & 63.0 & 64.1 \\
\hline RB & 50.4 & 49.9 & 47.9 & 45.1 & 44.9 & 44.7 & 49.5 & 67.7 & 65.6 & 62.8 & 62.2 \\
\hline TB & 55.7 & 56.8 & 56.4 & 59.7 & 63.8 & 62.1 & 60.9 & 63.9 & 64.9 & 66.3 & 68.2 \\
\hline \multicolumn{10}{|c|}{ Vegetables } \\
\hline IR & 70.0 & 69.0 & 69.5 & 70.4 & 66.0 & 65.3 & 61.6 & 61.7 & 58.9 & 59.7 & 58.1 \\
\hline RB & 77.6 & 73.6 & 73.4 & 65.2 & 74.2 & 73.2 & 70.5 & 66.7 & 68.3 & 63.2 & 57.5 \\
\hline TB & 21.1 & 22.2 & 22.2 & 23.4 & 22.8 & 16.9 & 21.9 & 21.9 & 19.8 & 21.2 & 19.0 \\
\hline \multicolumn{10}{|c|}{ Eggs } \\
\hline IR & 172.0 & 169.9 & 172.3 & 167.1 & 167.0 & 164.8 & 160.2 & 160.7 & 162.1 & 161.5 & 162.5 \\
\hline RB & 37.2 & 35.2 & 34.3 & 33.1 & 32.8 & 34.8 & 35.8 & 36.8 & 41.1 & 40.1 & 38.6 \\
\hline TB & 51.2 & 43.7 & 41.7 & 41.0 & 39.2 & 40.0 & 40.4 & 40.0 & 39.2 & 39.7 & 41.7 \\
\hline
\end{tabular}

TABLE II. CONSUMPTION OF BASIC FOODSTUFFS PER CAPITA PER YEAR, KG

\begin{tabular}{|c|c|c|c|c|c|c|c|c|c|c|c|}
\hline Ye & 007 & 2008 & 2009 & 201 & & & & & & & 20 \\
\hline \multicolumn{12}{|c|}{ Potatoes (recommended rational consumption rate of $90 \mathrm{~kg} /$ year/person) } \\
\hline IR & 123 & 120 & 115 & 114 & 111 & 113 & 106 & 106 & 99 & 97 & 97 \\
\hline RB & 87 & 90 & 89 & 88 & 88 & 91 & 90 & 88 & 85 & 80 & 86 \\
\hline TB & 91 & 106 & 106 & 105 & 103 & 103 & 107 & 103 & 104 & 100 & 103 \\
\hline \multicolumn{12}{|c|}{ Milk (recommended rational consumption rate of $325 \mathrm{~kg} /$ year/person) } \\
\hline IR & 184 & 193 & 192 & 190 & 198 & 202 & 199 & 200 & 197 & 193 & 194 \\
\hline RB & 240 & 249 & 256 & 258 & 257 & 252 & 250 & 236 & 230 & 222 & 207 \\
\hline TB & 244 & 244 & 245 & 245 & 249 & 247 & 247 & 251 & 250 & 249 & 244 \\
\hline \multicolumn{12}{|c|}{ Meat (recommended rational consumption rate of $73 \mathrm{~kg} /$ year/person) } \\
\hline IR & 57 & 61 & 61 & 62 & 66 & 69 & 70 & 70 & 68 & 68 & 67 \\
\hline RB & 57 & 59 & 59 & 62 & 63 & 66 & 66 & 65 & 64 & 63 & 66 \\
\hline \begin{tabular}{|l|l} 
TB \\
\end{tabular} & 66 & \begin{tabular}{|l|}
67 \\
\end{tabular} & 67 & 68 & 68 & 72 & 72 & 73 & 72 & 73 & 71 \\
\hline \multicolumn{12}{|c|}{ Vegetables (recommended rational consumption rate of $140 \mathrm{~kg} / \mathrm{year} / \mathrm{person})$} \\
\hline IR & 75 & 76 & 75 & 72 & 75 & 78 & 73 & 73 & 71 & 71 & 70 \\
\hline RB & 54 & 57 & 56 & 57 & 61 & 62 & 62 & 60 & 60 & 59 & 57 \\
\hline TB & 73 & 85 & 86 & 84 & 86 & 83 & 85 & 88 & \begin{tabular}{|l|l} 
\\
\end{tabular} & 87 & \begin{tabular}{|l|}
87 \\
\end{tabular} \\
\hline \multicolumn{12}{|c|}{ Eggs (recommended rational consumption rate of 260 pc/year/person) } \\
\hline $\mathrm{IR}$ & 189 & 194 & 196 & 203 & 208 & 213 & 219 & 224 & 230 & 232 & 233 \\
\hline RB & 171 & 188 & 191 & 200 & 202 & 210 & 206 & 206 & 207 & 196 & 202 \\
\hline TB & 155 & 156 & 162 & 168 & 170 & 174 & 168 & 170 & 171 & 169 & 159 \\
\hline
\end{tabular}

The analysis of the food supply of Russian constituent entities belonging to the Baikal region allowed us to draw the following conclusions.

a) The level of self-sufficiency of the main agricultural products from 2007 to 2017.

- Positive dynamics are observed in meat and meat products, negative-for potatoes, milk and dairy products (except for TB), vegetables and gourds, eggs and egg products (except for RB).

- Only for one type - eggs and egg products - full selfsufficiency was achieved in one of the regions $(162.5 \%$ in IR for 2017; in RB and SC the situation is catastrophic, 38.6 and $41.7 \%$ respectively). Due to natural and climatic conditions, locally produced vegetables and gourds cannot fully supply Baikal region (IR - 58.1\%, RB - 57.5\%, TB - 19\% in 2017; almost all the regions have shown a significant decline in the level of self-sufficiency in vegetables since 2007).

- The situation is quite favorable in terms of the availability of potatoes and milk (with the exception of RB) - despite the decline in indicators over the last decade, the Baikal region supplies at least $3 / 4$ of the needs of the manufacturing sector and the population in these products.

b) Average per capita consumption of basic foodstuffs from 2007 to 2017

- The standards of rational nutrition in the Baikal region are observed for potatoes; for meat and meat products, the average per capita consumption of the population is approaching the established medical standards (in 2017 , in the IR $-91.8 \%$ of the established norm, RB $90.4 \%$, TB $-97.3 \%$ ). For milk and dairy products, vegetables and gourds, eggs and egg products, the recommended rational consumption standards are not 
The realization of this mission is possible within the met; thus, the diet of the population of the Baikal region is not balanced.

- From 2007 to 2017, the average per capita consumption of meat and meat products, eggs and egg products increased. For other types of food, trends are contradictory and multidirectional.

- In the Baikal region, livestock production is traditionally developed; in the crop industry due to historical conditions, natural and climatic factors and other objective reasons, there are low crop yields and productivity, high fund and energy intensity, strict environmental restrictions on economic activity due to the "Baikal factor". When assessing the structure of the local diet, we should keep in mind that the protein-lipid type of nutrition in the region is the norm. However, in the post-reform period, there was a significant shift towards the protein-carbohydrate type; there is still a trend of over-consumption of carbohydrates, negatively affecting the health of the population.

In general, the situation with food supply in the Baikal region can be called unsatisfactory. To improve the efficiency of the regional food market, the system of interregional and interstate food links and the modernization of agricultural production based on the principles of environmentallyoriented agricultural environmental management are needed. Since the Baikal region is not only peripheral, but also border (RB has a common border with Mongolia, TB-with Mongolia and China), in the structure of food import-export, imported goods occupy a significant share. In 2014-2018, the top 20 delivered goods included: vegetables and some edible root vegetables and tubers (IR - \$44.32 million, RB - \$70.96 million, TB - $\$ 687.03$ million), edible fruits and nuts (IR $\$ 37.36$ million, $\mathrm{RB}$ - \$51.49 million, TB - \$473.63 million), RB was importing large volumes of meat and edible meat offal - \$31.7 million; dairy products, eggs, and natural honey - \$10.79 million; TB imported sugar and confectioneries $\$ 8.03$ million. Meanwhile, the use of financial instruments to support open and protected ground vegetable production and modern investment practices in the vegetable industry would provide a real opportunity to reduce imports by raising the level of self-sufficiency of the Baikal region with vegetables.

B. The formation of an inter-regional agroecological cluster producing organic livestock products will bring synergistic socio-ecological and economic effect to the Baikal region and contribute to the realization of a unique regional mission

The Baikal region's AIC shows a significant lag in key social and economic indicators from the average Russian level. Meanwhile, since the end of 2018, RB and TB have become part of the Far Eastern Federal District (DFO), whose regions belong to the group of priority strategic territories of the Russian Federation. In this study, the Baikal region is considered as a single socio-ecological and economic system, global mission of which is to prevent the degradation of the unique natural ecosystem of Lake Baikal (a UNESCO World Heritage Site) by moving to eco-oriented innovative development, particularly in the AIC sector. framework of the scenario of differentiated spatial growth, according to which all regions of the country should develop relatively systematically, based on their existing potential. The Country's Spatial Development Strategy, approved in 2019, includes promising specializations of regional agro-industrial production: food production (IR, RB), crop and livestock production (RB, TB). For IR, production of drinks is also a promising area; crop and livestock production are unpromising, but critically important for the economy of IR, for TB-food production [2].

Of the above, the greatest prospects are seen in livestock, as the AIC of the Baikal region has a pronounced livestock orientation. The majority of the regional agricultural products is produced in the households of the population, and the TB has a catastrophic situation (large-scale agricultural production is almost nonexistent - the share of agricultural organizations in the volume of production is only $1.4 \%$ ), while in the IR there is parity between agricultural organizations and personal farms (agricultural holdings of the region produce $49 \%$ of pork, $56 \%$ of poultry, $82 \%$ of eggs, $64 \%$ of dairy products). The long-term active state support of PF (peasant farms) led to a slight increase in their share in the agricultural sector, but farming still could not become the agricultural locomotive of the regional economy. Moreover, the number of PF has decreased noticeably in recent years, which corresponds to global Russian trends: due to unfavorable conditions of the economy (excessive administrative pressure, regulations, fees, fines, checks, concentration of state support in large agricultural holdings) of 308 thousand PF, which operated in the country in 2012, by January 1, 2019 there was only 188 technological practices is one of the conditions for the effective development of agriculture: excessive reduction of any categories of farms leads to a decrease in technological diversity and a decline in the sustainability of agrarian economy [15].

The solution is seen in the merger of "Prussian" and "American" ways of developing the way of production in agriculture, which provides for large-scale integration of farms within the agricultural holdings, clusters and cooperatives [11]. Competitive advantages of a cluster at the same time are the presence of horizontal and vertical connections, the stimulation of innovative activities in cooperating and integrating production, dissipativity, the dual nature of interaction of cluster elements, expressed in the contradictory unity of competition and cooperation $[11,12]$.

The transition of the world economy to a higher level of systemic functioning due to the marginal increase in the concentration of matter, energy and information in the $21 \mathrm{st}$ century leads to the widespread consolidation and merger of companies, the formation of network structures, the growth of science-intensiveness and the number of clusters, including agro-industrial [1].

Currently, industry intercluster networks are actively being formed in Europe: according to the European Cluster Observatory, 2,101 clusters with a total staff of about 42 million people (of which $11.5 \%$ operate in the agricultural thousand left (40\% reduction). Meanwhile, the diversity of 
sector) are active in the economic sectors of 28 countries in Western and Eastern Europe. In 2007, the Food Cluster Initiative was launched, with FINE (Food Innovation Network Europe) project including European clusters in the food industry as its prototype. In addition to the FINE project that underlies the Initiative, 11 other active projects are taking part in the latter to develop the innovative potential of the food industry through universities and research centers [17].

According to the Russian Cluster Observatory, more than 200 cluster initiatives are being implemented in the country, with about 41 projects $(18.6 \%)$ in the agricultural sector of the economy. As agricultural scholars rightly point out, the evolution of AIC management systems naturally moves from simple to complex, from small to large; in a globalized environment, the process of growing intensification, consolidation and competition is inevitable, leading to the emergence of cooperative-integrated structures [11, 12]. In Russian practice, considerable attention is paid to the formation and development of small-form agro-industrial clusters, which can become a platform for the integration and cooperation of personal and peasant farms and the application of public-private partnership mechanisms [11, 12, 15]. This approach allows to support small forms of economic management, the social importance of which in conservation and development of the village is often underestimated. We need to note that agriculture is a multifunctional environment as its processes have social, environmental, cultural, recreational and other effects.

In the first Russian studies on the process of cluster formation in the AIC, the emphasis was on the principle of social orientation of cluster technologies: the cluster approach was not only a means of achieving the goals of economic policy, but also a powerful tool of social transformation, aimed at increasing employment and the level of well-being of the population, the improvement of social infrastructure $[9,18$, 19].

The growing dissemination of the concept of green economy, seen as a new vector of sustainable development, has led to a shift in emphasis in the theory of cluster development of the AIC: resource and energy conservation, reducing the negative impact on the environment, environmentally sustainable economic progress are brought into focus. In relation to the agricultural sector, the prospects of introducing more efficient technologies for deep processing of raw materials, recycling, hybrid, opening and closing technologies, which allow to implement the principles of the closed-loop economy, thus helping to solve the global problem of resource exhaustion, were considered.

In the context of the fourth industrial revolution, the AIC takes on a new socio-economic context associated with the digitalization of the agricultural sector. In agriculture abroad, the transition to digital technologies has begun, the processes of intellectualization ("smart" farming), automation and robotization of agricultural labor (the USA, China, Japan, Brazil, EU countries actively practiced the use of "agricultural" drones and robots. Goldman Sachs predicts that by 2021, the AIC sector will become the second largest in the use of drones; in 2023, the penetration rate of drones in
China's AIC is expected to exceed 40\%, and sales of such devices in monetary terms will reach 16 billion yuan $(\$ 2.4$ billion)). The introduction of new technological solutions, ranging from automated agricultural equipment and drones that monitor harvests to a wide range of IoT sensors that, for example, measure soil moisture and monitor the health of farm animals, will revolutionize the industry in the near future, as some experts are already using the term "Agriculture 4.0" that was first used at the World Government Summit [14]. This should provide a cumulative beneficial effect in the social sphere (digitalization can increase the consumption of food by two to three times without changing the level of income of the population), in the economy (increased productivity, lower costs and trade margin on agricultural products), and in the ecosystem (increasing resource- and energy efficiency). Currently, the Ministry of Agriculture of the Russian Federation is implementing a departmental project "Digital Agriculture" designed for 2019-2024; over 35 regions of the Russian Federation are involved in the pilot project.

Because of their innovative nature, clusters are the optimal form of organizing agribusiness using digital technologies. In our opinion, the functioning of agroecological clusters will bring the region a synergistic socio-ecological and economic effect, based on the rapid development using platform technologies that have intersectoral importance (ICT, biotechnology, energy, environmental management technologies, etc.), and network solutions.

The promising specialization of the inter-territorial agroecological cluster in the Baikal region may be organic livestock farming, the main elements of which do not contradict the implementation of a unique regional mission. Concentration of cattle in small and medium-sized farms, a historical pastoral model based on nomadic livestock production and promoting organic produce in numerous farms, which provide employment and preservation of ethnoecological traditions of adaptive environmental management, the need to take into account environmental externality and social benefits in assessing the efficiency of agricultural production in the Baikal region makes it appropriate to use a cluster form of agro-economy organization [20].

\section{CONCLUSION}

Significant regional differences due to the huge size of territory of Russia require a differentiated approach to food supply and flexible regional policies, taking into account the characteristics of the food market of each region and the specifics of its agricultural sector. The approach to the development of the Baikal region as a united socio-ecological and economic system involves ensuring environmentally friendly innovative growth in those areas of activity where the region has unique advantages. The Baikal region belongs to the peripheral, border areas included in the risky farming zone. Deep structural problems in the regional food system are a consequence of the underdeveloped infrastructure, imperfections of the mechanism of interregional interaction in the food sector and the outdated model of the development of the agricultural sector. The formation of an inter-regional agroecological cluster specializing in the production of 
[8] A.S. Khukhrin, "Synergic Approach to Developing the Agroindustrial Clusters Economy of agricultural and processing enterprises," vol. 8, 2014, pp. 44-50.

anic livestock products can bring a synergistic effect to the region, which will manifest in the stabilization of the rural economy, the development of the social sphere, and the preservation of ecosystem stability and sustainability.

\section{ACKNOWLEDGMENTS}

This work was made within the grant "Young Researchers of the East Siberia State University of Technology and Management". The authors express their gratitude to the management of the East Siberia State University of Technology and Management for their comprehensive support of the research activity of its employees.

\section{REFERENCES}

[1] A.S. Khukhrin, O.I. Bundina, I.U. Agnaeva "Agro-industrial Clusters in Russia: the Contours of the Future," Economy of agricultural and processing enterprises, vol. 12, 2016, pp. 11-23.

[2] A.I. Altukhov, "The Country's Agricultural Production Needs a New Concept of Location and Specialization," Economy of agricultural and processing enterprises, vol. 8, 2019, pp. 7-14, DOI: 10.31442/02352494-2019-0-8-7-14.

[3] M. Porter, On Competition. Boston, 1998.

[4] M. Delgado, M. Porter, S. Stern, "Clusters, Convergence, And Economic Performance," Research Policy, vol. 43(10), 2014, pp. 17851799.

[5] L.S. Markov, M.V. Petukhova, K.Y. Ivanova, "The Cluster Policy Organizational Structures," Journal of the New Economic Association, vol. 3(27), 2015, pp. 140-162.

[6] M.A. Yagolnitser, L.N. Perepetchko, "Innovative Development And Economic Growth," Journal of Advanced Research in Law and Economics, vol. 8(1), 2017, pp. 261-266.

[7] A.S. Khukhrin, I.Yu. Agnaeva, N.P. Tolmacheva, O.I. Bundina, "Development of agro-industrial clusters in Russia: synergetic approach", International Journal of Econometrics and Financial Management, vol. 2, 2014, pp. 130-135.

[9] A.E. Romanov, V. P. Arashukov, "Agroindustrial clusters of Russia - a new myth or a prospect?," Economics of agricultural and processing enterprises, vol. 7, 2008, pp. 27-33.

[10] A.S. Boytsov, A.I. Kostyaev, "Regarding to Clusters Theory and Cluster Approach," Economy of agricultural and processing enterprises, vol. 9, 2009, pp. 25-31.

[11] S.N. Butorin, A.V. Bogoviz, "The Innovational And Production Approach To Management Of Economic Subjects Of The Agrarian Sector," Advances in Intelligent Systems and Computing, vol. 726 2019, pp. 758-773.

[12] S.N. Butorin, I.S. Sandu, "Formation Of Innovative Infrastructure Of A Control System In Agrarian Sector," Agrarian And Industrial Complex: Economy New Zealand Management, vol. 9, 2017, p. 39

[13] A.N. Semin, A.V. Kurdymov, "International Food Security Regulation Assessment," Opcion, vol. 34(85), 2018, pp. 628-651.

[14] "Plans and prospects for the development of the Russian AIC for 2019," the Cooperative Project of the Federal Ministry of Food and Agriculture "German-Russian Agricultural and Political Dialogue." Retrieved from https://agrardialog.ru/files/prints/plani_i_perspektivi_razvitiya_apk_ross iyskoy_federatsii_na_2019_god.pdf.

[15] A.V. Golubev, "Import Substitution In The Russian Agri-Food Market: Expectations And Capabilities," Economic Issues, vol. 3, 2016, pp. 4662.

[16] O.G. Ovchinnikov, "State Policy of Rural Development in the USA Experience for Russia Economy of agricultural and processing enterprises," vol. 2, 2019, pp. 12-18

[17] T.I. Volkova, "Development of Agro-Industrial Clusters in the World Economy of agricultural and processing enterprises," vol.1, 2017, pp. 61-66.

[18] V.A. Kundius, A.N. Kharchenko, "Prospects For The Balanced Development Of The Economy Of The Agrarian Region," Agrarian And Industrial Complex: Economy New Zealand Management, vol. 2, 2014, p. 76.

[19] V.A. Kundius, "Cluster Approach To Realization Of Innovation Development Strategy For The Agroindustrial Complex Of The Region," Economy of region, vol. 4(28), 2011, pp. 117-133.

[20] T.A. Boldanov, L.G. Namzhilova, A.K. Tulokhonov, "Historical Experience Of Organic Agriculture Management In Transbaikalia," Geography and natural resource, vol. 39(3), 2018, pp. 248-253, DOI: $10.1134 / \mathrm{S} 1875372818030083$ 